\title{
OBITUARY
}

\section{DR. BENNETT}

DR. BENNETT was born in Leicester seventy years ago-the son of a former Mayor of the town. He studied medicine at Owens College, Manchester, becoming M.R.C.S., L.R.C.P., and, later, M.D. (London). He was House Surgeon to the Manchester Infirmary and afterwards to St. Mary's Hospital. Coming back to Leicester he was appointed an Hon. Asst. Physician to the Infirmary. But he was soon attracted to the subject of Diseases of the Ear and Throat and, as was then customary for anyone wishing to specialise, he went to Vienna to study. On his return he became the first Aural Surgeon to the Infirmary.

$\mathrm{He}$ endured all the hardships of a pioneer. An odd bed or two -here in a medical, there in a surgical ward-and scattered all over the hospital-was granted to him. At the Out-Patient Department no House Surgeon attended, and not even a nurse was provided. Dr. Bennett himself paid for a nurse from outside. Almost all the operations, other than tonsils and adenoids, were claimed, as their prerogative, by the general surgeons. Dr. Bennett held the position for nearly thirty years, and it is a testimony to his enthusiasm, to his skill, and to his tact and his personal charm that during these years he won the esteem of all his colleagues, vindicated all the claims of his specialty and, on his retirement, left his department well established, well equipped, and an important centre in the practice of the hospital.

Dr. Bennett was fortunate in that he had many interests outside the narrow limits of specialism. Science, and especially the department of Geology, had a fascination for him. Twenty years after his graduation in Medicine he took the B.Sc. degree. Many holidays in SwitzerJand were devoted to the study of glacial action. Nearer home he was the authority on the rocks of Charnwood Forest, a geological puzzle. He was, for years, the perpetual President of the Leicester Library and Philosophical Society. Often, too, he lectured to crowded and appreciative audiences on his favourite subject. He was for years a member of the old School Board and did good work.

He was a great lover of music. He might often be seen playing the 'cello in some local orchestra. He was on the Committee of the Leicester University College, and was deeply interested in the Museum, to which he presented valuable specimens and models. Indeed, only a few hours before his sudden death he was present at a committee meeting.

During the War he served as Aural Specialist in the Base Hospital, and in this work, as in all he undertook, he gave of the best that was 


\section{Reviews of Books}

in him. He was for many years a member of our Section of Laryngology; but, always a man of keen feeling and strong conviction, he disapproved of its sudden action towards the foreign members after the War and sent in his resignation. Consequently he was not well known to the younger members. But he will be remembered by many of the seniors, and, in his own town, he will be greatly mourned and much missed.

A. L. M.

\section{REVIEWS OF BOOKS}

\section{Cancer of the Larynx. By Sir St Clair Thomson and Lionel Colledge.}

It is of the utmost value that from time to time some attempt should be made to take stock of the progress of any sustained endeavour, and when this endeavour is a fight against such a dire disease as cancer of the larynx, it is of great importance that the position should be reviewed. It is fortunate when this can be done authoritatively and by one who has been in the forefront of the campaign for a considerable time and who has done much to direct the disposition of the forces against the enemy. It is, I think, true to say that in this country the experience of Sir St Clair Thomson with regard to cancer of the larynx is unique, and one naturally expects that this experience should be reflected in the present volume in which he has combined with $\mathrm{Mr}$. Colledge to present the subject before us.

Nor are our expectations disappointed.

The book naturally falls into two halves, of which the larger portion is devoted to intrinsic cancer and which is based mainly on the personal experience of Sir St Clair Thomson from a large number of cases and a series of no less than 74 laryngofissure operations.

After an interesting historical survey, the pathology of cancer of the vocal cord is discussed and attention is drawn to the work of Broders and his method of grading the degree of malignancy from the microscopic appearances. It is interesting to note that when this was checked on a series of 60 cases that had been operated on, the percentage of recurrence was highest in the expected group. This suggests that the histological character of the growth should be taken into account in deciding what type of operation is appropriate for a particular case.

Analysis of the cases also brings out the important fact that the favourite location of intrinsic cancer is the central portion or anterior 